\title{
Setting out into practice: Preparing for the future, today
}

\author{
J. W. Awori Hayanga, MD, MPH, and Parth Amin, MD $^{\mathrm{b}}$
}

\footnotetext{
From the ${ }^{a}$ Division of Lung Transplantation, Department of Cardiothoracic Surgery, University of Pittsburgh Medical Center, Pittsburgh, Pa; and ${ }^{\mathrm{b}}$ Department of Cardiothoracic Surgery, Western Michigan University School of Medicine, Kalamazoo, Mich.

Disclosures: Authors have nothing to disclose with regard to commercial support.

Received for publication Nov 2, 2016; revisions received March 25, 2017; accepted for publication May 8, 2017; available ahead of print June 7, 2017.

Address for reprints: J.W. Awori Hayanga, MD, MPH, Department of Cardiothoracic Surgery, University of Pittsburgh Medical Center, 200 Lothrop St, Pittsburgh, PA 15213 (E-mail: jhayanga@me.com).

J Thorac Cardiovasc Surg 2017;154:1340-2

$0022-5223 / \$ 36.00$

Copyright (c) 2017 by The American Association for Thoracic Surgery

http://dx.doi.org/10.1016/j.jtcvs.2017.05.001
}

Although improving clinical judgment is a lifelong learning process, training programs prepare us for patient care more reliably than for any of the other aspects of practice. However, the transition from trainee to attending surgeon is difficult. One must prepare to shift from a busy position of effortless, seemingly boundless opportunity with limited responsibility to one of somewhat limited opportunity yet boundless responsibility and expectation. Preoperative decision making, intraoperative technique, and postoperative intensive care are daily aspects of our lives for many years. In today's healthcare environment, clinical ability is one of only many requirements for a successful long-term career. Unfortunately, there is no formal, and generally a lack of informal, education during our formative residency years. Furthermore, the healthcare landscape is changing so rapidly that a voluminous reference would be instantly outdated on publication. We have in the following editorial tried to include a framework for some general areas in which most recent graduates might consistently find themselves without sufficient exposure during traditional training programs.

\section{QUALITY}

Quality cardiac and thoracic surgical care was previously delivered through peer evaluation, process improvements that focused on a surgeon's perioperative judgment, and intraoperative technique coupled with an informal education pertaining to nonclinical issues during the formative residency years. Although outcomes in the last 20 years have improved, peer evaluation and self-reflection are the least secularly valued quality performance measures. Both national cardiac surgical societies and payers have determined that overall mortality, hospital readmission, and complications are quantifiable and predictable. Hospitals and insurance companies are quick to partner up for the promise of increased payment for a previously established set of quantifiable outcomes. Although the reasons for these changes are beyond the scope of the article, cardiothoracic surgeons entering the workforce must contend with the concept of "risk" in a much different capacity than our more senior colleagues did when they started practice.

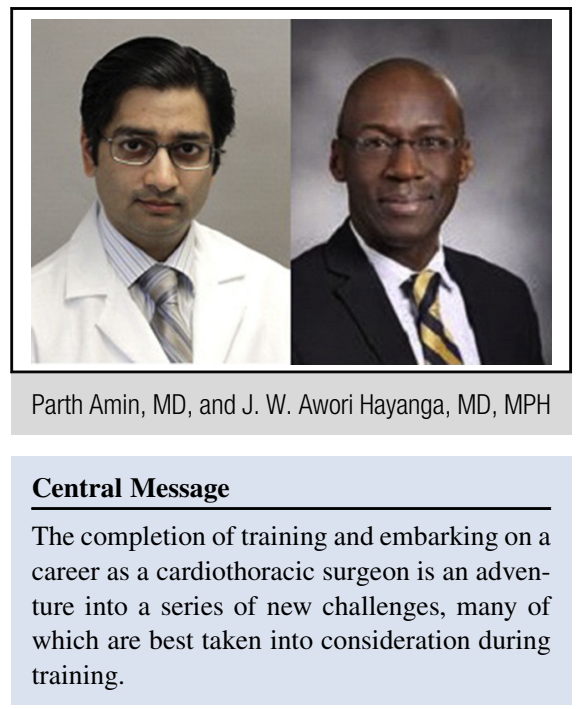

See Editorial Commentary page 1343.

The conventional wisdom dealt with the importance of local reputation with more seasoned cardiac surgeons and cardiologists. In the cardiothoracic "new world order," not only does conventional wisdom hold true, but comparisons with what are considered national benchmarks are equally, if not more important. Understanding these benchmarks, when they arise, and how they are measured are of utmost importance for a graduating surgeon. Some more cynical practitioners might suggest that institutional public reporting of outcomes has become the battle cry for most payers. This is in large part because the definition of quality can then be manipulated to the end of decreasing reimbursement. Nevertheless, a positive by-product has been an ever increasing focus on guaranteeing outcomes in what is otherwise an extremely high-risk specialty.

To understand risk, there are a few levels of scrutiny that need to be understood. Certainly, partners, peers, and referring cardiologists are important team members who help guide quality. At present, however, hospital-level quality and safety officers are also charged with assessing quality in surgeons. Usually, this is done by process and quality-improvement initiatives, and real-time/rapid evaluation of in-hospital or 30-day mortalities, analysis of readmissions, and evaluation of other outcome measures such as ventilator days, postoperative atrial fibrillation rates, postoperative acute kidney injury, and so on. The last layers include public reporting through the Society of Thoracic Surgeons, mined Medicare hospital data through 
for-profit companies such as Healthgrades, and various other mined registries.

Every surgeon has always kept a record of outcomes near to his or her own heart, but now these records are, in effect, a matter of public record. Surgeons must be very cautious in performing high-risk cases when starting out, even if these cases have known high mortalities. Such intense scrutiny, in a setting of small volumes, may create a statistical situation that is difficult to defend. Mentorship and administrative support are very important in this regard. A simple, highyield approach to risk assessment for young surgeons is to speak to other surgeons. Ask them their approach and things they learned, and take into account the environment they are in (academic vs small community). Meet with the Society of Thoracic Surgeons data coordinator at your present institution. Get a sense of what data are submitted and what weaknesses are present in the current institution. Last, find out what the mentorship plan is in the new practice you join. These basic steps should be sorted out even before starting a new position on completion of formalized training.

\section{ADMINISTRATIVE RESPONSIBILITIES}

The first 2 years of practice can be an extremely busy time during which one makes multiple commitments in a bid to stay the proverbial "affable, able, and available." However, the sudden exposure to administrative responsibilities, such as relative value unit targets and quality benchmarks, are not necessarily part of any formal training curriculum. The administrative responsibilities demand attention paid to practice infrastructural, billing, administrative support, and calendar management. One must take the time to become savvy in this regard and to seek the balance between being helpful and overcommitting, so as not to spread oneself too thin. Indeed, the benefit of good mentoring cannot be overstated in this regard, and the ability to discuss cases preoperatively, timetabling, and strategic planning are of great utility. Mentors also can help to guide junior faculty in regard to which societies to join, which meetings to attend, and which connections to make all in a bid to prepare for the next phase of one's career. The deliberate acquisition of skills and understanding of the business of coding and reimbursement proffer a significant advantage. To achieve this may involve attending courses, didactic and online courses specifically geared toward establishing working knowledge of the Current Procedural Terminology and International Classification of Diseases, 10th Revision, coding systems. This is invaluable in understanding the nuances in billing. However, one must also devise a means of balancing the clinical and nonclinical demands of the job to live up to the expectation of the surgical leadership, as well as those of collaborating physicians and the referral base. In this vein, taking and passing the boards is a pivotal part of the adjustment to maintain one's credibility and, indeed, credentialing.

\section{POLITICAL ASSESSMENT}

The nuances of joining a multipartner practice occasionally may involve the possibility of being placed at odds with other partners and suddenly becoming perceived as a competitor, and thus creating an unexpected set of intramural political challenges. During the interview process, it is thus worthwhile to pay attention to the different stakeholders and actors within the practice, as well as the culture of the practice and how partners treat one another. There is likely something to gain and something to be lost by the introduction of any new partner, and there may very well be an existing political rift into which one finds oneself thrust on entering a new practice. Existing alliances may dictate the tenor of relationships within the practice and may in turn determine the relative level of assistance or obstruction one will receive as a new junior partner. Mentally preparing for the situations and having thought through them beforehand should help in navigating through these delicate scenarios. For this reason, it is often worthwhile to have multiple mentors for different categories, including clinical, academic, administrative, and even psychosocial. Drawing on the wisdom of many is of great value indeed.

Once again, it is helpful to evaluate the environment before joining a practice. Find out about turnover, speak to surgeons who have left, and speak to referring physicians about turnover, reputation, and practice patterns. The same set of questions should be asked of everyone, and this may allow a reasonable mental map of the geopolitical atmosphere, the key players involved, and the danger spots to avoid. When starting in practice, keep opinions quiet, and stay out of the limelight.

\section{FINANCIAL}

The often dramatic change in remuneration from training salary to that of an attending cardiothoracic surgeon calls for thoughtful financial planning and an understanding and appreciation for such financial items as disability insurance, life insurance, tax deferment accounts, debt reconciliation, 529k plans, wills, retirement, and investment options. The lack of financial literacy that is often a characteristic of many surgeons serves as a big disadvantage if steps are not actively taken to remedy this by seeking advice and taking prompt action. This is particularly important in single-income families with heavy educational debt. One must balance the desire to acquire attractive assets with the newly increased salary against the need to establish solid financial stability, pay off debts, and start investing for the future and retirement. It is also of utmost importance to realize that many physicians are so focused and inundated with clinical care that it may seem attractive to blindly 
follow the advice of a financial advisor. A true understanding of financial objections and options requires multiple discussions with financial advisors and colleagues, as well as time spent educating oneself on these matters.

Meet with representatives at the benefits office, read independently from the plethora of books that exist on the subject, and speak to trusted colleagues and friends. The absolute minimum issues to understand include retirement plans (401k, 403b, and 457b plan), college savings plans for children (529k plans), life insurance (whole life vs term life), basic investing (stocks, bonds, mutual funds), disability insurance, and emergency planning (wills, advance directives). Last, take time to establish financial goals and set realistic spending parameters until loans are paid off and retirement accounts can be started.

\section{ACADEMIC RESEARCH}

Establishing a niche and directing one's clinical and research efforts in a unified direction are endeavors that one should seek to establish as early as possible. This will set the scene for the development of an area of expertise to allow one to develop into a content expert and provide a unique service at a sophisticated level. This often requires the benevolence and guidance of a clinical and administrative mentor early in one's career and demands time and commitment on both sides. Mentors also can help to guide junior faculty in regard to which societies to join, which meetings to attend, and which connections to make all in a bid to prepare them for the next career phase. For those pursuing an academic career, plans should advisedly be laid during residency starting with a discussion with the program director/chair. One must seek advice as to how to find the time to first learn the necessary techniques and skills, and second to negotiate the time away from clinical practice to allow for an active research program. A similar argument holds true for establishing a clinical research platform for which one must begin to hone techniques for reviewing manuscripts and developing those for publication. It would serve well to begin amassing a database of patients and procedures during training. One should be aware of and carefully observe the rules of patient confidentiality regarding data collection and storage while accruing data.

\section{CONCLUSIONS}

Overall, the nuances of starting a postfellowship career are hinged on first establishing a trusted network of opinions from colleagues who are stakeholders in your success while still maintaining an appropriate work-life balance. Being able to receive critical and constructive advice is valuable, and remaining dedicated to excellence of care and steady improvement despite inevitable occasional setbacks is a defining characteristic of starting out as successfully as possible. The shift into full clinical practice is difficult but can be managed efficiently through planning and seeking appropriate mentorship. Above all, however, one must be guided by the devotion toward excellent patient care and view this as the most significant factor guiding decision-making at the bedside and in the operating room. It remains our main objective to first do no harm (primum non nocere) regardless of remuneration or external metrics. 